\title{
Article
}

\section{Restraining Good Practice: Reviewing evidence of the effects of restraint from the perspective of service users and mental health professionals in the United Kingdom (UK)}

Cusack, Pauline, McAndrew, S., Cusack, F. and Warne, T.

Available at http://clok.uclan.ac.uk/13731/

Cusack, Pauline ORCID: 0000-0002-9685-0215, McAndrew, S., Cusack, F. and Warne, T. (2016) Restraining Good Practice: Reviewing evidence of the effects of restraint from the perspective of service users and mental health professionals in the United Kingdom (UK). International Journal of Law and Psychiatry, 46 (May-Ju). pp. 20-26. ISSN 0160-2527

It is advisable to refer to the publisher's version if you intend to cite from the work. http://dx.doi.org/10.1016/j.ijp.2016.02.023

For more information about UCLan's research in this area go to

http://www.uclan.ac.uk/researchgroups/ and search for <name of research Group>.

For information about Research generally at UCLan please go to http://www.uclan.ac.uk/research/

All outputs in CLoK are protected by Intellectual Property Rights law, including Copyright law. Copyright, IPR and Moral Rights for the works on this site are retained by the individual authors and/or other copyright owners. Terms and conditions for use of this material are defined in the policies page. 
Title: Restraining Good Practice: Reviewing evidence of the effects of restraint from the perspective of service users and mental health professionals in the United Kingdom (UK)

\begin{abstract}
Safeguarding, balancing the concept of risk with the need for public protection and its implication for the lives of individuals, is an important facet of contemporary mental health care. Integral to safeguarding is the protection of human rights; the right to live free from torture, inhuman or degrading treatment, and having the right to liberty, security, respect and privacy. Professionals are required to recognise all of these rights when delivering care to vulnerable people. In the United Kingdom (UK) there has been growing public concern regarding abusive practices in institutions, with a number of unacceptable methods of restraint being identified as a feature of care, particularly in mental health care. In keeping with the service user movement, and following a review of the literature, this paper discusses the evidence regarding restraint from the perspectives of service users and professionals within mental health services and considers the implications for future practice and research. In reviewing the literature findings revealed restraint can be a form of abuse, it's inappropriate use often being a consequence of fear, neglect and lack of using de-escalation techniques. Using restraint in this way can have negative implications for the well-being of service users and mental health professionals alike.
\end{abstract}

Key Words: abusive practice, de-escalation, human rights, mental health, restraint, safeguarding 


\section{Introduction}

While safeguarding is an international issue, recent scandals in care settings in the UK have caused major public concern (Wainwright 2012). Undercover filming within care settings found abusive practices, with illegal and abusive restraint being a significant feature (Flynn 2012). The impact of such scandals can lead to a tendency for practitioners to adopt defensive practice, thus reducing opportunity for positive risk taking (Arnoldi, 2009), the latter playing a central role in assisting personal development and enhancing a person's quality of life (Sharland, 2006). Managing positive risk taking is a process of compromise and negotiation. It requires an increase in potential benefits, and a rigorous process for planning and monitoring risk taking strategies and reviewing the results (Titterton 2005). A lack of positive risk taking compromises service user involvement in risk assessment, at times the latter being unaware that a risk assessment has been carried out (Langan \& Lindlow 2004). While service users are now recognised as experts in their own right (Lammers \& Happell 2003; Warne \& McAndrew, 2004), the issue of their involvement in risk assessment has, to date, not been adequately addressed (Langan 2009). In ignoring such expertise, the service user is confined to a state of anomie with little or no choice in terms of the interventions used to address their health and social care needs (Warne \& McAndrew, 2006). For professionals, the unconscious nature of many of their responses to service user expertise regarding risk assessment, only serve to reinforce the traditional professional/client dichotomy, the former dominating the latter. This situation has the potential to lead to more social controls being put into place, restraint being one of them which, in essence, can impact negatively on a person's dignity, human rights and full citizenship (Morrall \& Muir-Cochrane 2002).

\subsection{Restraint: the legal and political context}


The Mental Capacity Act (MCA) for England and Wales (2005) states that "someone is using restraint if they use force, or threaten to use force, to make someone do something they are resisting, or restrict a person's freedom of movement, whether they are resisting or not” (MCA 2005). Whilst legislation and policy attempts to define and outline when restraint may be used, the types of restraint employed by professionals vary in different situations. Different types of restraint include: physical, including holding a person or blocking movement; mechanical, using equipment or furniture to prevent/restrict movement; chemical, using prescribed medication on a regular basis to manage behaviour; technological, such as 'tagging', door pads; and psychological, depriving a person of possessions/equipment or constantly directing a person not to do something (Commission for Social Care Inspection, 2007). In using any of the aforementioned, professionals need to recognise that preventing a person from doing as they wish, may contravene their human rights (Owen \& Meyer 2009). MIND (2009) echoed the need for a rights-based approach when providing services for those who have mental health problems, suggesting that systems tend to be paternalistic, failing to take account of preferences from the individual's perspective and disempowering people from making decisions that affect their lives. Guiding principles for the promotion of human rights for people with mental disorder were outlines by the World Health Organisation (WHO) (1996) however, where practices of restraint contravene such principles it could be interpreted as abusive restraint. For example, section 2 of Principle 8, 'Standards of Care', states, "Every patient should be protected from harm, including unjustified medication, abuse by other patients, staff or others, or other acts causing mental distress or physical discomfort” (WHO, 1996, p16). Data analysed from the National Audit Survey for people with learning disabilities, (Healthcare Commission for Audit Inspection, 2007), of facilities for people with learning disabilities in England, found a consistent trend of using medication as restraint over physical intervention, with $80 \%$ of services using Pro Re Nata (PRN), 'medication as required', excessively (Sturmey, 2009). 
In the UK, the inception of policy that tried to address adult abuse and the management of risk was the Department of Health (DH) guidance, No Secrets, (DH, 2000). 'No Secrets' outlined adult protection (later referred to as safeguarding adults), offering guidance to agencies involved in incidents of abuse and providing a framework for the development of local policy. 'No Secrets' (DH, 2000) also defined adult vulnerability and abuse to help establish clear terms of reference that could be used in fieldwork settings. However, since the inception of 'No Secrets', other legislation has been implemented. The Deprivation of Liberty Safeguards (DoLS), introduced via an addendum to the Mental Capacity Act 2005 (Ministry of Justice 2008), provides a framework for people who need to be deprived of their liberty, such as those who are at risk of harm to self or others and who do not have mental capacity in relation to making decisions regarding their care and treatment (Ministry of Justice 2008). On $1^{\text {st }}$ April 2015, The Care Act (2014) came into statue, overriding the policy around safeguarding set out in 'No Secrets'. The Care Act (2014) sets out a clear legal framework for how local authorities and other service providers should protect adults at risk of abuse or neglect. In the UK, on 19 March 2014, 'Deprivation of liberty' was defined by a Supreme Court ruling, when they unanimously ruled on two cases; $P$ v Cheshire West and Chester Council and P \& $Q v$ Surrey County Council [2014] (UKSC, 19). In P v Cheshire West, P, a profoundly disabled man, was deprived of his liberty by the complete and effective control exercised over his life by those looking after him. In the second case, P \& Q v Surrey County council, two sisters P, who had a moderate to severe learning disability, and Q, who had a mild learning disability were deemed to have been deprived of their liberty. Whilst P lived with her foster mother and Q resided in a funded NHS residential home, both did not have the option of leaving their respective care settings. The Supreme Court ruled that those who lack the capacity to make decisions about their care and residence and, under the responsibility of the state, are subject to continuous 
supervision and control and lack the option to leave their care setting are unlawfully being deprived of their liberty.

In effect the ruling rejected the Appeal Court's decision, re-affirming the original decision made by the Court of Protection. In reaching this decision the Supreme Court identified that to determine whether a person who is mentally incapacitated is being deprived of their liberty, the following 'acid test' should be applied: Is the person subject to continuous supervision and control? Is the person free to leave? The focus is not on the person's ability to express a desire to leave, but on what those with control over their care arrangements would do if they sought to leave. The Supreme Court went on to clarify that in all cases, the following are not relevant when applying the test: The person's compliance or lack of objection; the relative normality of the placement (whatever the comparison made); the reason or purpose behind a particular placement.

While the Act defines situations that may constitute a deprivation of liberty, the use of restraint as outlined in the MCA (2005) may not be deemed to be a deprivation of liberty. The European Court of Human Rights states that a deprivation of liberty is dependent on the individual circumstances of each case and there is no single definition (Council of Europe/European Court of Human Rights 2014). In the UK the National Institute for Clinical Excellence (NICE) (2005) guidance regarding restraint advised that account be taken of 'necessity', with reference to the European Convention on Human Rights, including Article 2 (right to life); Article 3 (the right to be free from torture or inhuman or degrading treatment or punishment); Article 5 (the right to liberty and security of person save in prescribed cases); and Article 8 (the right to respect for private and family life), and the principle of ‘proportionality' (HRA 1998). However, the MCA (2005) can be used to restrain a person under differing circumstances and conditions (RadcliffesLeBrasseur 2010), such as confining a person to an environment that has door locks 
they are unable to open or allowing prescription drugs to be used in order to sedate someone.

\subsection{Implications of legislation and policy on practice}

Regardless of the subjective nature of the use of restraint being right or wrong, in a minority of cases it can be abusive, particularly when no formal risk assessment has been carried out or where there has been no exploration of alternatives, involving the restrained person and/or their relatives (DH, 2014). While the balance of risk and safety can be difficult to calculate, the use of abusive restraint can have negative implications for both service users and professionals alike. The remainder of this paper reports on a review of available evidence that specifically focuses on the implications of using restraint from the perspective of users of mental health services and professionals delivering such services in the UK.

\section{Reviewing the literature}

\subsection{Search strategy}

To elicit selective papers relating to the implications of using restraint from the perspective of users of mental health services and those implementing it, a systematic approach was used to search the data bases. Inclusion criteria comprised all papers published in English since 2000, this being the year that No Secrets (DH 2000) was implemented, those focusing on adults, 18 years and over, papers reporting on service user and/or professional perspectives of restraint and those studies undertaken in mental health and/ or an associated residential settings, usually for those with a learning disability, within the UK.

The terms 'risk' 'abuse' 'restraint' 'adult service user perspectives' 'mental health services' and 'professional perspectives', the latter making use of synonyms such as social worker, nurse, mental health worker, doctors, were listed to initiate the search. Using the terms generated, the following databases, MEDLINE, British Nursing Index (BNI) Cumulative Index 
to Nursing and Allied Health (CINAHL); Social Care on Line, Social Sciences Abstracts (SSA), SWETSWISE, Cochrane Library, Applied Social Sciences Index and Abstracts (ASSIA), and PsychINFO were searched. Boolean techniques, using 'and' with the differing search terms allowed the search to be narrowed to a number of useful hits. In addition, Google scholar, having comprehensive coverage of academic literature in health and social care (Gehanno et al. 2013), was also searched. Additionally, hand searching was employed as referenced articles can often identify research for further exploration (Taylor et al. 2003).

With regard to restraint being considered an abusive practice from the perspectives of service users and those providing care, and the inclusion criteria identified above, the initial search yielded 13 papers. On further examination of the papers, two were duplicates and four were not related to mental health. The results of the search indicated that in the last 14 years relevant studies equated to seven published papers. Of the seven studies identified; four were qualitative studies (Bonner et al. 2002; Fish \& Culshaw, 2005; Jones \& Kroese, 2006; Perkins et al. 2012), one study used mixed methods (Duxbury et al. 2002), one study made use of a survey comprising of quantitative and qualitative questions (Lees et al. 2003) and one was a quantitative study (Foster et al. 2007). See Table 1 below for an overview of the studies.

Table 1

\begin{tabular}{|l|l|l|l|l|l|}
\hline Author/s & $\begin{array}{l}\text { Research } \\
\text { Paradigm }\end{array}$ & $\begin{array}{l}\text { No. of } \\
\text { subjects }\end{array}$ & Data Collection & $\begin{array}{l}\text { Data } \\
\text { Analysis }\end{array}$ & Main Findings \\
\hline $\begin{array}{l}\text { Bonner, et } \\
\text { al. (2002) }\end{array}$ & Qualitative & $\begin{array}{l}12 \text { staff } \\
6 \mathrm{pts}\end{array}$ & Interviews & $\begin{array}{l}\text { Thematic } \\
\text { Analysis }\end{array}$ & $\begin{array}{l}\text { Problematic unsettled environment Service } \\
\text { Users (Sus) alerted staff when disturbed but } \\
\text { ignored } \\
\text { SUs find restraint distressing Re- } \\
\text { traumatisation can occur } \\
\text { Staff only debrief } \\
\text { Restraint common when unfamiliar staff on } \\
\text { duty }\end{array}$ \\
\hline $\begin{array}{l}\text { Duxbury } \\
(2002)\end{array}$ & $\begin{array}{l}\text { Mixed } \\
\text { Methods }\end{array}$ & $\begin{array}{l}80 \text { pts } \\
72 \text { nurses } \\
10 \text { medics }\end{array}$ & $\begin{array}{l}\text { Questionnaire } \\
\text { Incident forms } \\
\text { Interviews }\end{array}$ & $\begin{array}{l}\text { Factor } \\
\text { Analysis } \\
\text { \& } \\
\text { Thematic } \\
\text { analysis }\end{array}$ & $\begin{array}{l}\text { Staff controlling } \\
\text { Poor communication \& environment factors } \\
\text { equate to aggression } \\
\text { Verbal aggression most common } \\
\text { Medication/restraint/seclusion commonly } \\
\text { used in response to aggression }\end{array}$ \\
\hline
\end{tabular}




\begin{tabular}{|c|c|c|c|c|c|}
\hline & & & & & $\begin{array}{l}\text { Patients ( PT) \& staff believed they were } \\
\text { victims } \\
\text { Inadequate organisation \& management } \\
\text { leads to restraint }\end{array}$ \\
\hline $\begin{array}{l}\text { Fish \& } \\
\text { Culshaw } \\
\text { (2005) }\end{array}$ & Qualitative & $\begin{array}{l}7 \text { nurse } \\
\text { assistants } \\
6 \text { nurses } \\
3 \text { clinical } \\
\text { team leaders } \\
9 \text { service } \\
\text { users [SU] }\end{array}$ & $\begin{array}{l}\text { Unstructured } \\
\text { interviews - } \\
\text { participatory } \\
\text { approach } \\
\text { participant-led }\end{array}$ & $\begin{array}{l}\text { Phenomen } \\
\text { ological } \\
\text { analysis. }\end{array}$ & $\begin{array}{l}\text { Restraint: frustrating \& re-traumatising. } \\
\text { Staff - feel guilty in using restraint. SUs felt } \\
\text { restraint was a punishment } \\
\text { SUs knew restraint used to prevent harm } \\
\text { SUs cited provocation and situational factors } \\
\text { equated to aggression } \\
\text { Staff felt aggression due to a factors built up } \\
\text { over time }\end{array}$ \\
\hline $\begin{array}{l}\text { Jones \& } \\
\text { Kroese } \\
\text { (2006) }\end{array}$ & Qualitative & $\begin{array}{l}10 \text { SUs } \\
\text { detained } \\
\text { under MHA } \\
\& \text { restrained } \\
\text { in last } 6 \\
\text { months } \\
\text { Managers } \\
\text { selected } \\
\text { people likely } \\
\text { to engage }\end{array}$ & $\begin{array}{l}\text { Semi-structured } \\
\text { interviews }\end{array}$ & $\begin{array}{l}\text { Thematic } \\
\text { Analysis }\end{array}$ & $\begin{array}{l}\text { SUs knew why restraint used, 50\% said it } \\
\text { did not help them calm down. } \\
\text { Not being listened to prompted aggression } \\
\text { Abusive restraint evident } \\
\text { Restraint followed interaction with staff } \\
\text { Being ignored after restraint difficult. } \\
\text { SUs believed poor coping skills \& poor } \\
\text { understanding of restraint made them } \\
\text { vulnerable to stress reactions following } \\
\text { restraint. } \\
\text { No de-briefing post-restraint problematic. }\end{array}$ \\
\hline $\begin{array}{l}\text { Lees et al. } \\
\text { (2003) }\end{array}$ & $\begin{array}{l}\text { Qual \& } \\
\text { Quant } \\
\text { Survey }\end{array}$ & 338 nurses & Survey & $\begin{array}{l}\text { Thematic } \\
\text { Analysis } \\
\& \\
\text { SPSS for } \\
\text { numerical } \\
\text { data }\end{array}$ & $\begin{array}{l}\text { Positive experience of restraint. } \\
\text { Concern re opportunity for abuse. } \\
\text { Negative attitudes of colleagues } \\
\text { Using restraint is demeaning } \\
\text { Staff have worse injuries than pts. } \\
\text { Poor organisation \& management contribute } \\
\text { to use of restraint }\end{array}$ \\
\hline $\begin{array}{l}\text { Foster et } \\
\text { al. (2007) }\end{array}$ & Quantitative & $\begin{array}{l}\text { Nurses on } 5 \\
\text { acute wards }\end{array}$ & $\begin{array}{l}\text { Completion of } \\
\text { SOARS-R }\end{array}$ & $\begin{array}{l}\text { SPSS/ } \\
\text { descriptive } \\
\text { statistics }\end{array}$ & $\begin{array}{l}\text { Staff often the target of aggression } \\
\text { Provocation due to denial of item } \\
\text { Staff fear likely to lead to restraint }\end{array}$ \\
\hline $\begin{array}{l}\text { Perkins, et } \\
\text { al. (2012) }\end{array}$ & Qualitative & 30 nurses & $\begin{array}{l}\text { 1:1 interviews } \\
\& \text { focus groups }\end{array}$ & $\begin{array}{l}\text { Thematic } \\
\text { Analysis }\end{array}$ & $\begin{array}{l}\text { Triggers; self-harm, aggression, violence, } \\
\text { ward demands, unknown SUs, unfamiliar } \\
\text { staff. } \\
\text { Restraint as deterrent for unacceptable } \\
\text { behaviour and as first line management }\end{array}$ \\
\hline
\end{tabular}

\subsection{Overview of the research strategies}

The studies reviewed have some shared strengths and limitations. Five of the studies (Duxbury 2002; Lees et al. 2003; Fish \& Culshaw, 2005; Foster et al. 2007; Perkins et al. 2012) gave voice specifically to mental health professionals regarding the use of restraint, while three (Bonner et al. 2002; Duxbury 2002; Jones \& Kroese, 2006 ) offered a voice to the service user. In Perkins et al.'s (2012) study there was lost opportunity in exploring restraint from the service user perspective as this would have been a useful strategy to triangulate data. In Duxbury's 
(2002) study the 'Management of Aggression and Violence Scale’ (MAVAS) was formulated for the purpose of the study, and used to analyse participants' views on patient aggression and subsequent action to manage such situations. The reliability of the MAVAS was established by using a test-retest procedure (Burns \& Grove 1993), with, according to the researcher, factor analysis being used to determine its validity. However, this is misleading as factor analysis is used to reduce the number of variables that can then be tested for their construct or criterion validity. Additionally, although Duxbury (2002) used semi-structured interviews with four service users, four nurses and three doctors, the specific interview findings were not presented in the paper.

Five of the studies used small samples (Bonner et al. 2002; Duxbury 2002; Fish \& Culshaw, 2005; Jones \& Kroese, 2006; Perkins et al. 2012), while Lees et al.'s (2003) study had a low response rate and, focusing on the last incident of restraint, had the potential to create bias. Three studies (Duxbury, 2002; Fish \& Culshaw, 2005; Foster et al., 2007) were carried out in one region, North-West England, making generalisations to other regions difficult, as they may have different policies, procedures and training, as well as different organisational cultures. However, regardless of sample size and where the studies took place, all have an important contribution to make in relation to gaining insight into the impact of using restraint from the perspective of professionals and service users who have experience of mental health and associated services.

\section{Research findings}

The findings from the studies can be organised into three themes (1) Triggers for restraint and taking control; (2) External forces and (3) Physical and emotional consequences.

\subsection{Triggers for restraint and taking control}


In four of the seven studies (Duxbury 2002; Fish \& Culshaw, 2005; Foster et al. 2007; Perkins et al. 2012) incidents of violence and aggression were cited as the main trigger for using restraint. It was reported that the majority of incidents had been preceded by the service user either physically assaulting or attempting to assault someone, or had been threatening physical violence (Duxbury 2002; Perkins et al. 2012). Foster et al.'s (2007) study indicated 5.7 of the incidents reported related to acts of verbal and physical aggression, with staff being the most common target (57.1\% of incidents). However, in Duxbury’s (2002) study, 70\% of incidents consisted of verbal abuse and threats, with verbal aggression accounting for most $(84.1 \%)$ of the incidents. However, violence and aggression were not always directed at staff, and Foster et al. (2007) found no significant differences in service user and staff targeted incidents. In their study, 48 incidents, where other service users had been the target, were reported, with verbal aggression and use of hand pushing accounting for $45.8 \%$ of cases.

Whilst incidents of aggression, whether they are physical or verbal threats, both staff and service users had their own perspectives on what triggered such behaviour. Service users felt that approaches on the part of the staff were controlling in nature, believing that poor communication and environmental factors often precede episodes of aggression (Bonner et al. 2002; Duxbury, 2002; Fish \& Culshaw, 2005; Jones \& Kroese, 2006). The notion of using restraint as a way of controlling behaviour was evident in five of the studies (Lees et al. 2003; Fish \& Culshaw, 2005; Jones \& Kroese, 2006; Foster et al. 2007; Perkins et al. 2012). However, in Duxbury's (2002) study the service users believed the use of restraint to control and reduce symptoms of illness when only $13.5 \%$ of incidents involved actual violence is inappropriate. In Perkins et al.'s study (2012) staff viewed restraint as a 'necessary evil', used to control behaviour and prevent violence, while Fish and Culshaw (2006) revealed conflicting perceptions between staff and service users as to why restraint was used. Staff reported that they used restraint as a last resort, while service users believed it was used, on occasion, as a 
punishment (Fish \& Culshaw, 2006). Threats to ward stability and functioning were also offered as important reasons for the decision to restrain individuals, being explicated in terms of avoiding behavioural disturbances that could potentially impact on other service users. The issue of using restraint as a form of control in Perkins et al.'s (2012) study related to staff making a distinct association with the service user's mental illness and their inability to control their behaviour. This finding was somewhat contradictory to that of the service users in Bonner et al.'s (2002) and Jones and Kroese's (2006) studies, where service users reported they had alerted staff to their disturbance prior to restraint, but felt ignored.

Taking into consideration people usually get admitted to acute inpatient care when their illness is at its worst, and their ability to control their behaviour is reduced, restraint in acute mental health services could be accepted as normal practice (Perkins et al. 2012). However, it was also reported that fear of aggression may motivate staff to use physical means, such as restraint and/or seclusion, to manage what is considered to be unacceptable behaviour (Bonner et al. 2002; Duxbury 2002; Foster et al. 2007). With regard to fear as a motivator, the nurses in Perkins et al.'s (2012) study articulated how knowing a patient meant that they were aware of their pattern of behaviour and trigger points to aggression, making risk more predictable and de-escalation possible. Mirroring this, service users in Bonner et al.'s (2002) study suggested that staff who did not know them, for example agency staff, increased the likelihood of restraint being used.

While what staff might consider 'unacceptable behaviour' can be managed in a variety of ways, the evidence suggests that medication, restraint or seclusion are the most popular approaches (Duxbury 2002; Lees et al. 2003; Fisher \& Culshaw, 2005; Jones \& Kroese’s 2006; Foster et al. 2007; Perkins et al. 2012). Having a de-escalation strategy, involving good communication, was reported as an important approach in dealing with unacceptable behaviour (Duxbury 2002; Fisher \& Culshaw, 2005; Jones \& Kroese’s 2006; Foster et al. 2007; Perkins et al. 2012). In 
Foster et al.'s (2007) study the main technique for managing staff targeted incidents was talking to the service user (42.1\%), followed by seclusion (35.9\% of incidents). However, Perkins et al. (2012) found that everyday de-escalation, using communication, often involved directing the service user to modify his/her behaviour. Ironically this was reported as the least useful approach when service users were suffering from acute symptoms, with staff recognising that this could be provocative and escalate, what they described to be, 'unacceptable behaviour' (Perkins et al. 2012). Likewise, Duxbury (2002) identified that only 25\% of incidents involved de-escalation, while Foster et al. (2007) reported seclusion being employed in over a quarter of all incidents, with $22.83 \%$ resulting in the service user being physically restrained, as opposed to staff employing less restrictive methods. More concerning, Perkins et al. (2012) reported that while the nurses acknowledged that horizontal restraint should be used only as a last resort in a progressive step-wise approach, it was reported as the first method used by the majority of staff with no alternative restraint positions being tried. The main priority was to act swiftly, which tended to lead to the use of unsystematic restraint, rather than a progressive, graduated, sequenced response as recommended by NICE (2005).

While it is reassuring that the findings highlight communication being used to attain deescalation (Duxbury, 2002; Perkins et al., 2012), the decision to use physical restraint, such as seclusion, remains a concern. Indeed some professionals reported a tendency to use restraint too quickly, with a 'deck people first' and a 'bouncer mentality' (Lees et al. 2003). Sadly, for some, the experience of being restrained prevented their future engagement with services (Bonner et al. 2002).

\subsection{External forces}

In four of the studies reviewed (Bonner et al. 2002; Duxbury 2002; Lees et al. 2003; Perkins et al. 2012) external forces were seen as contributing to the use of restraint. Organisational 
demands and ward issues were considered partly responsible for creating an environment in which challenging behaviour developed and escalated (Duxbury 2002; Perkins et al. 2012). The ward environment was identified as a factor contributing to the use of restraint (Lees et al., 2003; Fish \& Culshaw, 2005). In Bonner et al.'s study (2002) staff cited an unsettled ward environment as a major contributor to using restraint, while Fish and Culshaw’s (2005) study mirrored this finding from a service user perspective. There was also a mirroring of service user and staff views in terms of the unsettling nature of the ward environment being related to unfamiliarity (Bonner et al., 2002; Perkins et al., 2012). With regard to staff, changes in the service user population meant they became cautious in dealing with those who they did not know well (Perkins et al. 2012), while Bonner et al.’s (2002) reported unfamiliar staff, equating to an increase in the risk of restraint being used.

\subsection{Physical and emotional consequences}

Six of the studies (Bonner et al. 2002; Lees et al. 2003; Fisher \& Culshaw, 2005; Jones \& Kroese’s 2006; Foster et al. 2007; Perkins et al. 2012) highlighted the physical and emotional consequences of restraint for staff and service users. It was suggested that physical interventions such as restraint often become a 'battleground' as each party tries to gain control (Perkins et al. 2012). As with any battleground, people get hurt and in Lees et al.'s (2003) study $13 \%$ of participants reported service user injury, whilst $21.6 \%$ reported staff injury as a consequence of restraint. Likewise, Foster et al. (2007) identified pain or injury being reported in $7.6 \%$ of incidents. However, the nature of injury differed between service users and staff; the former being reported as minor scratches and bruises, whereas the latter were reported as more serious injuries, including black eyes and broken noses (Lees et al. 2003). In contrast, in Foster et al.'s (2007) study incidents directed at other service users had severe consequences for those targeted, with a quarter reporting pain or the need for treatment. Considering that restraint is often used in response to aggressive behaviour, albeit physical or verbal, Foster et 
al. (2007) estimated that a nurse, working in the units where their research took place, would need to work for 10 years to experience an injury stemming from service user aggression. However, the consequences of restraint do not only manifest in terms of physical injury, emotional trauma is also reported as being problematic.

Staff and service users alike were reported to have experienced emotional distress in relation to the use of restraint. For staff, the consequences of using restraint included feeling threatened (Foster et al. 2007) and causing them distress and discomfort (Bonner et al. 2002). In Lees et al.'s (2003) study participants suggested the experience of physically restraining a service user was demeaning , with 3\% reporting the need to take sick leave following their last restraint use, due to the personal stress it caused.

Similarly, service users described powerful and distressing emotions relating to restraint (Bonner et al. 2002; Lees et al. 2003; Fish \& Culshaw, 2005). For example a participant in Bonner et al.'s (2002) study reported having been left in 'wet urine soaked clothing for three hours', whilst in Lees et al.'s (2003) study excessively long restraint (up to 6 hours) was reported. Just as behaviour on the part of service users was deemed to be unacceptable, such behaviours on the part of staff are also demeaning, distressing and therefore also unacceptable. In addition, and what professionals need to be cognisant of is, for a number of service users restraint has the potential to re-traumatise, due to past experiences of abuse, many having experienced physical or sexual abuse in childhood (Bonner et al. 2002; Fish \& Culshaw, 2005).

Dealing with the consequences of restraint can be difficult. Only Bonner et al. (2002) highlighted strategies used by staff to 'buffer' the consequences of restraint. These included helping each other out, good team work and having the facility for de-briefing. However, both Bonner et al. (2002) and Jones and Kroese (2006) reported de-briefing was not offered to service users, who reported feeling ignored post incident. 
The seven studies reviewed above all suggest that restraint is a feature of practice in mental health and associated settings and has implications for those receiving and those delivering care. Each study identifies inappropriate use of restraint with negative consequences for service users and professionals alike. While restraint is used to control what staff deemed to be inappropriate behaviour, being controlling appears to give rise to verbal and physical aggression. Environmental factors may impact on the professional's decision to restrain, but there is a mismatch between the level of disturbance on the part of the service user and the response to such by staff invoking restraint. However, while both service users and those delivering care recognise the place of restraint in contemporary mental health care, the way in which it is sometimes used can breach human rights with negative consequences, such as fear, physical injury and emotional distress for both parties.

\section{Discussion}

The findings identified above can be discussed at three levels; the micro, individual level; the meso, an organisational level; and the macro level, within the wider socio-political context.

\subsection{The micro level: individual level}

At the micro level restraint being used inappropriately appears to be recognised by staff and service users alike. Professionals suggested that in some instances restraint was used too quickly and there was concern expressed about a 'bouncer mentality', (Lees et al. 2003), an attitude similar to that found in the Winterbourne Report (Flynn 2012). However, regardless of restraint being used inappropriately, some staff expressed being uncomfortable with using restraint per se, their own experiences of distress and discomfort mirroring those of service users (Bonner et al. 2002; Duxbury 2002; Lees et al. 2003; Fish \& Culshaw, 2005). Participants in one study (Lees et al. 2003) believed restraint was demeaning for service users, raising the question as to why restraint is so readily used. 
Restraint can have a negative impact on the interpersonal relationships between staff and service users, with both parties feeling victims of restraint (Duxbury 2002; Lees et al. 2003). While evidence suggests service users believed they were victims of controlling staff and staff believing they are victims of service user aggression; the juxtaposition of such beliefs creates problematic interactions for both parties (Duxbury 2002). It could be argued that users of mental health services are perhaps those who would benefit most from having a therapeutic relationship with those providing care (Warne \& McAndrew, 2004). As a number of people diagnosed with mental health problems have experienced abusive relationships earlier in life, restraint has the potential to reassert distressing memories (Bonner et al. 2002; Fish \& Cumshaw 2005). In terms of defensive practice, it has been suggested that one explanation is that people with a history of abuse seek restraint as a form of contact (Lees et al. 2003), however, the potential to re-traumatise must not be underestimated. It could be suggested that if the service user, in seeking out interpersonal contact creates vulnerability on the part of staff, this may lead to a feeling of discomfort, but one which outweighs the discomfort staff experience when using restraint. However, perhaps it is nurturance rather than restraint that could be more productive in such situations.

Fear was also a pertinent feature of restraint for service users and professionals alike. For service users fear engendered by previous restraint experiences led them to disengage from services (Bonner et al. 2002), while the use of restraint was motivated by staff's fear of potential aggressive behaviour (Duxbury 2002; Foster et al. 2007; Perkins et al. 2012). When professionals consider service users to be dangerous, aggressive, or difficult to manage, restraint and seclusion are reported to be used in an arbitrary way (Alldred et al. 2006). In some instances fear prompted staff to be over-cautious in responding to risk, by acting too hastily in respect of restraint (Bonner et al. 2002; Duxbury 2002; Lees et al. 2003; Perkins et al. 2012). Further, fear of incidents escalating to violence, resulted in an overestimation of the perceived 
threat, preventing staff from looking for alternative ways of providing more therapeutic containment (Duxbury 2002: Foster et al. 2007; Perkins et al. 2012) and subsequently reducing future opportunity for positive risk taking (Arnoldi 2009).

Positive interpersonal interaction and good communication were recognised as preventative approaches in avoiding restraint, but were not always present. However, while the importance of therapeutic interaction was recognised, service users reported that they were often ignored despite alerting staff to their feelings of disturbance (Bonner et al. 2002; Lees et al. 2002; Foster et al. 2007). Similarly, evidence suggests that while staff value de-briefing following restraint, the same opportunity is not afforded to service users (Bonner et al. 2002; Jones \& Kroese 2006). The need for better communication and the opportunity to talk to staff has been recognised as a good strategy for avoiding restraint (Fish \& Culshaw, 2005; Owen \& Meyer, 2009) and one that could easily be utilised within all mental health and social care settings.

\subsection{The meso level: organisational issues}

The ward environment was reported as problematic in five of the seven studies (Bonner et al. 2002; Duxbury 2002; Lees et al. 2003; Fish \& Culshaw, 2005; Perkins et al. 2012). An environment that is unsettling for service users was considered a potential initiator of aggressive behaviour (Bonner et al. 2002; Lees et al. 2003; Fish \& Culshaw, 2005). At a pragmatic level, lack of space and unsafe furniture were cited as attributes of a poor physical environment (Lees et al. 2003). At a more complex level, the atmosphere within the environment was said to have provoked incidents leading to restraint (Fish \& Culshaw, 2005; Foster et al. 2007). For example, it was reported that some staff viewed restraint as a 'necessary evil' in controlling behaviour and preventing violence, thus leading to the normalisation of the practice of restraint (Perkins et al. 2012). Such beliefs often become enmeshed within the 
pervading culture and may contribute to the difficulties of introducing changes in practice (Pereira et al. 2006).

Organisational issues such as understaffing and the regular use of agency staff were factors associated with the use of restraint (Lee et al. 2003; Perkins et al. 2012; Flynn 2012). It was suggested staff were cautious in dealing with service users who they did not know well, believing that a sense of knowing a person helped predict behaviours that might trigger aggression, but at the same time has the potential to perpetuate restraint as a first line approach (Perkins et al. 2012). Likewise, service users had a negative view of agency staff, believing that they were more vulnerable to restraint when in their care (Bonner et al. 2002). With regard to unfamiliarity between staff and service users, the subjective nature of risk assessment is also problematic. Risk assessment is not only dependent upon the values and confidence of the person assessing the risk, but it also calls into question who has the expertise to determine risk (Arnoldi 2009). With regard to the former, being free of such values could be interpreted as a positive asset of agency staff, but the confidence of such people may be compromised when they are in unfamiliar situations. Furthermore, there may be fear of recrimination should a person be injured whilst in their care, as the socio-cultural nature of organisations place absolute priority on a safety first approach (Titterton 2005). In terms of expertise in assessing risk, perceptions vary amongst individuals working with vulnerable people (Anderson, 2006). Four of the above studies (Bonner et al. 2002; Lees et al. 2003; Jones \& Kroese, 2006; Foster et al. 2007) found that service users recognised and reported their own disturbance prior to being restrained. Other studies noted that, within the same organisation, some staff are more likely than others to use restraint (Jones \& Kroese, 2006; Bowers \& Crompton 2012; Perkins et al. 2012), demonstrating that not involving the service user and/or their carer in the risk assessment process is, in itself, a risky business and one that contravenes the latest guidance (DH, 2014). 
However, while noting the above, it should also be considered that restraint itself has the potential to cause harm (Parkes et al. 2011; Stubbs \& Hollins 2011). Staff's skills and knowledge of restraint have been called into question, with both service user and staff injury being partly attributed to the use of different restraint techniques (Jones \& Kroese 2006). Indeed, within the literature a taxonomy of restraint is identified and includes the vertical and horizontal positions, the latter only deemed necessary as a last resort, but often being used as the first line of action (Whittington et al. 2006; Perkins et al. 2012), and the prone position now being banned due to its potential lethality (DH, 2014). Training and support for professionals who provide care is essential if inappropriate restraint is to be eliminated (Fossey et al. 2006; Jones \& Kroese, 2006; Owen \& Meyer 2009). It appears there is wide variation in policy, education and training and, where this does not exist, staff may not have the skills or direction to appropriately work with those who present with challenging behaviour (Deveau \& McGill 2008; Owen \& Meyer 2009). In the absence of appropriate training and policy, and where there is nothing in place for adequate monitoring of practice, organisations could be construed as neglectful.

\subsection{The macro level: wider socio-political context}

In the wider context, a 'risk society' can be seen as the catalyst for risk aversion (Beck 1992). Managers in organisations providing care to individuals are often challenged within the wider health and social care context. For example, if something goes wrong when risks are taken the media are likely to instigate a public outcry. Likewise, this often reinforces negative views of people who experience mental health problems, with relatives wanting a 'locked door policy' to prevent harm to their loved ones (Owen \& Meyer 2009). The notion of professional responsibility attached to risk, may account for the need to control a situation that is perceived to be threatening (Beck 1992; Duxbury 2002; Foster et al. 2007; Perkins et al. 2012). The culture of using control to avoid risk is demonstrated in the above studies, for example using 
excessive measures that are disproportionate to the threat posed or in keeping with an individual’s needs (Duxbury 2002; Lees et al. 2003; Perkins et al. 2012).

The UK government's agenda to promote dignity and choice (DH 2007) are in contrast to findings where restraint was considered by staff as demeaning in nature, yet the practice normalised and/or excessive (Bonner et al. 2002; Duxbury 2002; Lees et al. 2003; Foster et al. 2007; Perkins et al. 2012). Such practices challenge human rights, such as that of having a life free from degrading treatment and not to have one's liberty deprived, (HRA 1998). The MCA (2005) clarifies that restraint, in the context of restricting a person's movements, is permissible only in order to prevent harm and should be a proportionate response in relation to the likelihood and seriousness of harm (MCA 2005). People have a right to live a life free from abuse, (HRA 1998) and institutions should intervene 'proportionately' to protect individuals, (Association of Directors of Social Services, 2005). However, while legislation and policy provide parameters with regard to the use of restraint, disproportionate responses in relation to aggression and threats were reported in several of the studies reviewed (Duxbury 2002; Lees et al. 2003; Perkins et al. 2012).

It is argued that we live in a neo-liberal society that promotes individual choice and control and that health and social care are conceptualised within this political and economic framework (Webb, 2006). However, the concepts of choice and personal control contrast with a culture of using restraint as a form of containment within institutions (Lees et al. 2003; Sturmey 2009; Perkins et al. 2012). While cuts in public sector expenditure may account for why organisations promote a risk aversive culture, it would appear from the evidence presented in this paper that what service users and professionals alike want, is opportunity to build a therapeutic environment that facilitates nurturance through risk taking, rather than one of enforced containment. 


\section{Conclusion}

It would appear from the evidence available that the use of restraint in mental health and associated settings in the UK has detrimental effects for service users and professionals alike. At an individual level distress, physical injury and fear are common experiences for those receiving and delivering care, whilst at an organisational level environmental factors were identified as precipitants of aggressive behaviour and an over-zealous use of restraint. In the wider socio-political context the balance of risk and safety is difficult, particularly against a backdrop of public scandals, where unacceptable and, at times, unlawful methods of restraint have been perceived to be a prominent feature of care. People have the right to a life free from torture or inhuman or degrading treatment or punishment, the right to liberty and security, and respect and privacy. Professionals involved in delivering health and social care are required to recognise these rights, ensuring that the care delivered to vulnerable people is done so in a respectful, nurturing environment.

In addition to the recent Care Act (2014) and the Supreme Court ruling, the Mental Health Act (1983) code of practice (DH 2015) has also been updated, with emphasis on providing therapeutic and supportive environments, through using de-escalation approaches tailored to individual patient need, as a first line approach to minimise behavioural disturbances. In keeping with good practice, restrictions imposed on service users should be reasonable and proportionate to the risks associated with the behaviour being addressed and consistent with the guiding principles of the MCA (2005). Furthermore, professionals taking action to use restraint must reasonably believe that it is necessary to prevent harm and is a proportionate response to the likelihood and seriousness of harm to the person who lacks capacity. To achieve this health and social care professionals need to have a better understanding of the law and how it can best be implemented in the clinical setting, show service users respect by ensuring they have the same opportunities as staff with regard to communication, debriefing and decision 
making, and to prioritise developing therapeutic relationships and the nurturance of those for whom they are providing respectful, sensitive care. 


\section{$\underline{\text { References }}$}

Alldred, D.P. Petty, D.R. Bowie, P. Zermanskyt, A.G. \& Raynor, D.K. (2007) Antipsychotic prescribing patterns in care homes and relationship with dementia. The Psychiatric Bulletin, 31, p329-332

Association of Directors of Social Services. (2005) Safeguarding adults: A national framework of standards for good practice and outcomes in adult protection work. London, Association of Directors of Social Services.

Anderson, A. (2006) Media and risk. In Mythen G. and Walklate S. (eds) Beyond a risk society; critical reflections on risk and human security, pp115-131. Maidenhead, Open University Press.

Arnoldi, J. (2009) Risk. Cambridge, Polity Press

Beck, U. (1992) Risk society: towards a modernity. London, Sage.

Bonner, G. Lowe, T. Rawcliffe, D. \& Wellman, N. (2002). Trauma for all: a pilot study of the subjective experience of health in patients and staff in the UK. Journal of Psychiatry and Mental Health Nursing 9 (4) p465-473

Bowers, L. \& Crowder, M. (2012) Nursing staff numbers and their relationship to conflict and containment rates on a psychiatric wards- a cross sectional time series poisson regression study. International Journal of Nursing Studies 49 (1), p15-20

Burns, N. and Grove, S. (1993). The practice of nursing research conduct, critique and utilisation, $2^{\text {nd }}$ edition. London, W.B. Saunders.

Commission for Social Care Inspection (2007). Rights, risks and restraints: an exploration into the use of restraint in the care of older people. Newcastle, CSCI.

Council of Europe/ European court of human Rights (2014) Guide on article 5 of the Convention: right to Liberty and security. Strasburg, Council of Europe 
Department of Health (2000) No Secrets. Guidance on developing and implementing multiagency protection of vulnerable adults. London, HMSO.

Department of Health. (2007). Putting people first. Available at http://www.dh.gov.uk/prod_consum_dh/groups/dh_digitalassets/@dh/@en/documents/digital asset/dh_081119.pdf (Accessed $8^{\text {th }}$ June 2012)

Department of Health (2014) Positive and Pro Active Care: Reducing the need for restrictive interventions.

https://www.gov.uk/government/uploads/system/uploads/attachment_data/file/300291/JRA_ DH_Guidance_on_RH_Summary_web_accessible.pdf (Accessed 24th Sept 2014) Department of Health (2015). Mental Health Act 1983, code of Practice. London, HMSO DeVeau, R. \& McGill, P. (2009) Physical interventions for adults with intellectual disabilities: survey of use, policy, training and monitoring. Journal of Applied Research in Intellectual Disabilities, 22, p145-151

Duxbury, J. (2002). An evaluation of staff and patient views of and strategies employed to manage inpatient aggression and violence on one mental health unit: a pluralistic design. Journal of Psychiatric and Mental Health Nursing 9, p325-337

Fish, R. \& Culshaw, E. (2005). The last resort? Staff and client perspectives on physical intervention. Journal of Intellectual Disabilities, 9 (2), p93-107

Flynn, M. (2012). Serious case review, South Gloucester safeguarding board: Winterbourne View hospital. Gloucester, South Gloucester safeguarding board.

Fossey, J. Ballard, C. Juszczak, E. James, I. Alder, N. Jacoby, R. \& Howard, R. (2006) Effect of enhanced psychosocial care on antipsychotic use in nursing home residents with severe dementia: cluster randomised trial British Medical Journal 332: 756, p1-6.

Foster, C. Bowers, L. \& Nijman, H. (2007) Aggressive behaviour on acute psychiatric ward: prevalence, severity and management. Journal of Advanced Nursing 58 (2), p140-149 
Gehanno, J.F., Rollin, L. \& Darmoni, S. (2013). Is the coverage of Google Scholar enough to be used alone for systematic reviews? BMC Medical Informatics and Decision Making 13(1) 7

Healthcare Commission (2007). A life like no other: A national audit of specialist inpatient healthcare services for people with learning disabilities in England. Commission for Healthcare Audit and Inspection

Human Rights Act (1998). London. The Stationary Office.

Jones, P. \& Kroese, B.S. (2006) Service users’ views of physical restraint procedures in secure settings for people with learning disabilities. British Journal of Learning Disabilities, 35, p5054

Lammers, J. \& Happell, B. (2003) Consumer participation in mental health services: Looking from a consumer perspective. Journal of Psychiatric and Mental Health Nursing, vol.10, 4, p385 - 392

Langan, J. (2009). Mental health, risk, communication and data quality in an electronic age. The British Journal of Social Work (39) 3, p467-487

Langan, J. \& Lindlow, V. (2004) Service user involvement in risk assessment and management. Bristol, Policy Press.

Lees, S. Gray, R. Gournay, K. Wright, S. Parr, A.M. \& Sayer, J. (2003) Views of nursing staff on the use of restraint. Journal of Psychiatric and Mental Health Nursing 10, p 425-430 Mental Capacity Act (2005) London, HMSO.

Mind (2009) Safeguarding adults: a consultation of the Department of Health's review of No Secrets - Response from Mind. London. Mind.

Ministry of Justice (2008) Deprivation of liberty safeguards: code of practice to supplement the main Mental Capacity Act 2005 code of practice. London. The Stationery Office. 
Morrall, P. \& Muir-Cochrane, E. (2002). Naked social control: Seclusion and psychiatric nursing in post-liberal society. Advances in Mental Health, 1(2), 101-112

National Institute of Clinical Excellence (2005) Violence: The Short-term management of disturbed/violent behaviour in In-Patient Psychiatric Settings and Emergency Departments. London, NICE.

Owen, T. \& Meyer, J. (2009) Minimising the use of 'restraint' in care homes: challenge, dilemmas and positive approaches. London, SCIE.

Parkes, J. Thake, D. \& Price, M. (2011) Effect of seated restraint and the body size on lung function. Medicine Science and the Law 51, p177-181

Pereira, S. Dawson, P. \& Sarsam, M. (2006). The national survey of PICU and low secure units: 2 unit characteristics. Journal of Psychiatric Intensive Care, 2, p3-19

Perkins, E. Prosser, H. Riley, D. \& Whittington, R. (2012). Physical restraint in a therapeutic setting: a necessary evil? International Journal of Law and Psychiatry 35, p43-49

P v Cheshire West and Chester Council and P \& Q v Surrey County Council [2014] UKSC $19)$.

RadcliffesLeBrasseur, (2010). Mental health briefing 153. Available at www.rlblaw.com/...law-briefing-153---powers-of-restraint...2010).pdf (accessed $10^{\text {th }}$ December 2012)

Sharland, E. (2006). Young people, risk taking and risk making: Some thoughts for social work. British Journal of Social Work, 36(2), 247-265.

Stubbs, B. \& Hollins, L. (2011). Are physical intervention techniques likely to cause pain or injury when applied to manage the severely aggressive older adult? A survey of physiotherapist's expert views in the UK. Journal of Clinical Nursing 20, p2666-2675

Sturmey, P. (2009). Restraint, seclusion and PRN medication in English services for people with learning disabilities administered by the National Health Service: An analysis of the 2007 National Audit Survey. Journal of Applied Research in Intellectual Disabilities, 22, p140-144 Taylor, B. Dempster, M. \& Donnelly, M. (2003). Hidden Gems; systematically searching 
electronic databases for research publications for social work and social care. British Journal of Social Work 33, (4), p423-439

The Care Act (2014) London. HMSO

Titterton, M. (2005) Risk and risk taking in health and social welfare. London, Jessica Kingsley.

Wainwright, M. (2012) Four Staff to be charged with mistreating people with learning $\begin{array}{llll}\text { disability. } & \text { Guardian } & \text { Available }\end{array}$ http://www.guardian.co.uk/society/2012/aug/15/four-charged-mistreating-mentally-illpatients?INTCMP=SRCH. (Accessed $23^{\text {rd }}$ November 2012)

Warne, T. \& McAndrew, S. (Eds) (2004) Using Patient Experience in Nurse Education. Palgrave Macmillan Basingstoke.

Warne, T., \& McAndrew, S, (2006) Transferring anonymity for a few choice words. Nurse Education in Practice 6 (2) 63-68

Webb, S. (2006) Social work in a risk society: social and political perspectives. Basingstoke, Palgrave Macmillan.

Whittington, R. Lancaster, G.A.,Meehan, C. Lane, S. \& Riley, D. (2006) Physical restraint of patients in acute mental health care settings: patient, staff, and environmental factors associated with the use of a horizontal restraint position. Journal of Forensic Psychiatry \& Psychology 17, (2), p253-265

World Health Organization (1996) Guidelines for the promotion of human rights of persons with mental disorders. Geneva, WHO. 
